\title{
Translation, Validity and Reliability of Roles Conflict and Roles Ambiguity Inventory (RCRAI) among Trainee Counselors in Public Universities in Malaysia
}

Suhaili Arifin, Siti Salina Abdullah, Noor Syamilah Zakaria, Wan Marzuki Wan Jaafar, Zuhda Hussain

To Link this Article: http://dx.doi.org/10.6007/IJARBSS/v11-i12/11833

DOI:10.6007/IJARBSS/v11-i12/11833

Received: 02 October 2021, Revised: 04 November 2021, Accepted: 27 November 2021

Published Online: 13 December 2021

In-Text Citation: (Arifin et al., 2021)

To Cite this Article: Arifin, S., Abdullah, S. S., Zakaria, N. S., Jaafar, W. M. W., \& Hussain, Z. (2021). Translation, Validity and Reliability of Roles Conflict and Roles Ambiguity Inventory (RCRAI) among Trainee Counselors in Public Universities in Malaysia. International Journal of Academic Research in Business and Social Sciences, 11(12), 944-955.

Copyright: (c) 2021 The Author(s)

Published by Human Resource Management Academic Research Society (www.hrmars.com) This article is published under the Creative Commons Attribution (CC BY 4.0) license. Anyone may reproduce, distribute, translate and create derivative works of this article (for both commercial and non0-commercial purposes), subject to full attribution to the original publication and authors. The full terms of this license may be seen at: http://creativecommons.org/licences/by/4.0/legalcode

Vol. 11, No. 12, 2021, Pg. 944 - 955

Full Terms \& Conditions of access and use can be found at http://hrmars.com/index.php/pages/detail/publication-ethics 


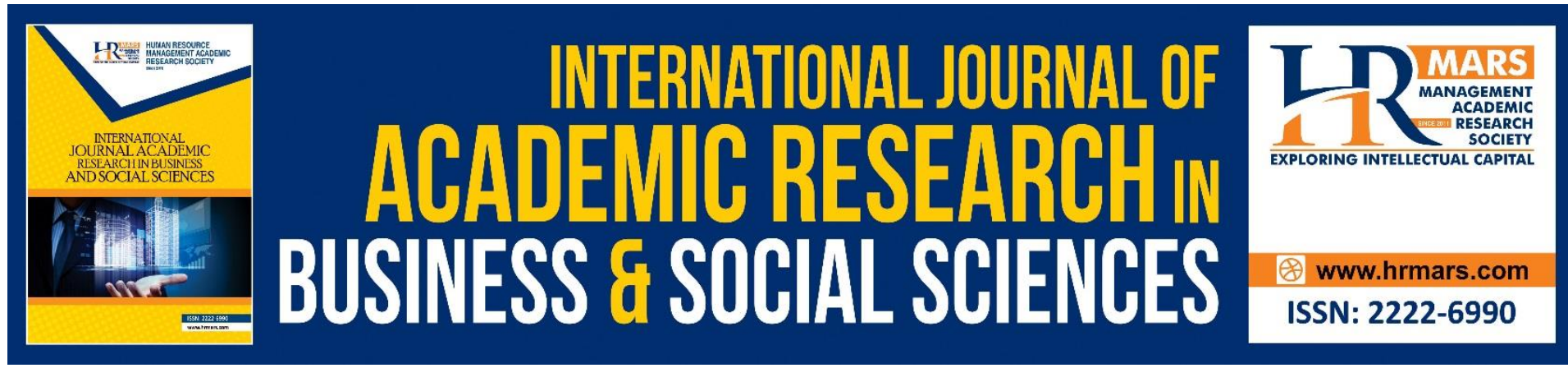

\title{
Translation, Validity and Reliability of Roles Conflict and Roles Ambiguity Inventory (RCRAI) among Trainee Counselors in Public Universities in Malaysia
}

\author{
Suhaili Arifin, Siti Salina Abdullah, Noor Syamilah Zakaria, Wan \\ Marzuki Wan Jaafar, Zuhda Hussain \\ Program of Counseling and Psychology, Faculty of Business, Economics and Social \\ Development, University Malaysia Terengganu, 21200 Kuala Nerus,
} MALAYSIA.

\begin{abstract}
The Roles Conflict and Roles Ambiguity Inventory (RCRAI) is developed by Olk \& Friedlander (1992) to measure the roles conflict and roles ambiguity experienced by trainee counselors in the clinical supervision. The purpose of this study was to translate RCRAI from English to Malay language, then to access the validity and reliability of the inventory within the Malay culture. This study used the back translation methods as suggested by Brislin, Lonner, and Thondike (1973). There were six translator panels appointed to conduct the translation process. The items in RCRAI were translated from English into Malay version according to local values and cultures by three panels, and then retranslated into original language by the remainder. Subsequently, the RCRAI in the Malay version was evaluated by four other experts to validate its contents. Next, the reliability analysis of RCRAI was conducted to trainee counselors at UPSI $n=30$, meanwhile in the real study, the analysis was run on nine public universities in Malaysia namely UPSI, UM, USIM, UPM, UUM, UMT, UIAM, UNIMAS, and UMS with the number of sample $n=204$. The result revealed the coefficient value of content validity obtained for each item is high with maximum value $=.95$ and minimum value $=.78$, while the coefficient value for each sub scale was also high with roles conflict $=.87$ and roles ambiguity $=.90$. Finally, the reliability value of RCRAl in the pilot study for roles conflict $\alpha=.78$ and roles ambiguity $\alpha=.86$; whereas in the actual study, the roles conflict and roles ambiguity were respectively $\alpha=.95$ and $\alpha=.95$ respectively. Conclusively, this study proved empirically that the RCRAI translation has succeeded, reliable and valid for Malaysian trainee counselors.
\end{abstract}

Keywords: Translation, Validity, Reliability, Roles Conflict and Roles Ambiguity Inventory, Trainee Counselors

\section{Introduction}

In Malaysia, for every counseling program offered at the Public Higher Learning Institutions and Private Higher Learning Institutions it is under the Malaysian Counselor 
Board. To ensure that the trainee counselors produced are competent and professional, the supervision process is made mandatory in the curriculum based on the Standard and the Requirements of the Counselor Training (Malaysian Counselor Board, 2015). Supervision is a form of examination on counselor activities by supervisor involving certain interaction processes aiming to empower the skills and expertise of counselors at the professional level. In the counseling profession, supervision is seen as a basic component on the development of the professional identity of trainee counselors who will serve in this profession (West, 2004), which is by increasing the skills, conceptualisation and delivery of services effectively to the clients (Bornsheuer-Boswell et al., 2013). Based on the British Association for Psychotherapy and Counselling (BACP, 2020) supervision is defined as "a specialised form of professional mentoring provided for practitioners responsible for undertaking challenging work with people."

Among the aims of the counseling supervision is to help counselors obtain professional development and personal characteristics, increase a sense of responsibility towards service delivery and counseling program, increase the competency level of the counselor (Ladany \& Bradley, 2010), preserve the welfare of the client and as a gatekeeper to the counseling profession (Bernard \& Goodyear, 2019). That said, previous literature suggests that one of the challenges of effective supervision on trainee counselors relates to the role difficulty (Arifin et al., 2019; Ladany \& Friedlander, 1995; Olk \& Friedlander, 1992). In the supervision, trainee counselors often face difficulty in playing their role well. According to Hess, Hess, \& Hess (2008), this happens because trainee counselors need to play their roles as student, trainee, counselor, and peer when undergoing training and during the supervision process. To learn to do and play all these roles at any one time would be difficult because every role necessitates different sets of behaviour (Holloway, 1984). This challenge can cause the trainee counselors to experience conflict and ambiguity and also the ambiguity on their roles (Olk \& Falender, 1992; Kulp, 2012), that will finally restrict their growth of competency in the supervision.

Olk and Friedlander (1992) have developed an instrument in their study related to the role conflict and role ambiguity in the context of counseling supervision. Role conflict happens when trainee counselors face an expectation that opposes their behaviour, and in turn, role ambiguity happens as trainee counselors are doubtful about the expectation in the supervision on their evaluation and performance (Olk \& Friedlander, 1992). The study involves two stages namely instrument construction stage and validity approval stage. The first stage involves Olk and Friedlander (1992) interviewing 6 supervisors and 9 trainee counselors from three stages namely practicum $n=3$, internship $n=3$, and post-internship $n=3$. All the trainess are selected from various settings like psychology training center, hospital, community mental health center, and mental health agency. Meanwhile the supervisors are aged between 30 and 50 years old, have the experience as counselor, used to supervise, and become supervisor, and conduct supervision 6.92 hours a week on average. The interview done requires every trainee counselor to explain in detail about their experience facing the role conflict and the role ambiguity in the supervision, and in turn, the supervisor is asked to explain about the role difficulty faced by the trainee counselors as has been observed.

Based on the content analysis done, 75 items have been constructed where 36 of them have measured the role conflict whereas 39 items measure the role ambiguity. Next, the items are selected and revised by 10 panel members which is $n=5$ supervisors having PhD and 5 trainee counselors at doctorate level that only represent clearly for the sub-scale of role conflict and sub-scale of role ambiguity. For items that are approved less than 80 percent will be removed 
from the instruments constructed. Finally, there are only 10 items of the role conflict and 19 items of role ambiguity after referring to the field experts and making the whole items total 29 items in RCRAI. Next, in the second stage, Olk and Friedlander (1992) have conducted two validity tests on the RCRAI involving (1) analysis factor; (2) criteria validity by predicting the role conflict sub-scale construct (RC) and role ambiguity (RA) will be significant on (a) satisfaction on the supervision; (b) work satisfaction in general; (c) anxiety; and (d) counseling experience. The outcome from the factor analysis is done using the varimax rotation showing that there are 6 factors with the eigenvalues $>1$. However, based on these three criteria namely scree test, parsimony, and interpretability finally two factors will be retained. For factor $1,35 \%$ variance where 16 from 19 items of factor RA have the value of $<.48$. Meanwhile, for the 3 items which is items $(3,9$, dan 10) it shows a higher correlation value on factor RC and low correlation value with factor RA.

The reliability analysis also shows that items $(3,9$, and 10$)$ are removed from factor RA, so the internal consistency value of RA will be added. Thus, these items are removed from factor RA and included in factor RC. Using the confirmatory factor analysis with both orthogonal and oblique rotation approaches produces the same results. Other than that, both these factors have a significant inter-correlation with the value of $r=.59, p<.01$. After the factor analysis is done, the latest version of RCRAI comprises of 16 items of RA and 13 items of RC that will be applied. Olk and Friedlander (1992) also carry out the predicted criteria validity which is RC and RA which is the predicting factor of Trainee Personnel Reaction Scale-Revised (TPRS-R), Job Descriptive Index (JDI), State Trait Anxiety Inventory (STAI), and counseling experience. Using the canonical analysis, the result obtained shows that both the RC and RA have a predicting factor on TPRS-R, JDI, STAI, and counseling experience with high significance value. As a whole, from the validity procedure done by Olk and Friedlander (1992) it shows that they have a good measurement tool and which is appropriate to be applied to measure the role conflict and role ambiguity experienced by trainee counselors in the supervision.

\section{Statement of Problem}

Counseling service is acknowledged in this country in 1998 when the government creates Act 580, 1998 Counselor Act and the establishment of Malaysian Counselor Board. The acknowledgment has made the counseling a controlled professional profession within the national law. This simultaneously causes a drastic increase in the demand for counseling training. To fulfill this demand, 11 public universities namely UKM, UPM, UPSI, USM, UM, UTM, UUM, UMS, UNIMAS, UMT, and USIM HELP have offered a graduate program and postgraduate program in this field through the endorsement of the Malaysian Counselor Board (Minister of higher Education Malaysia, 2011). As counseling programs are mostly offered by public universities, it is the responsibility of the government to ensure that the production of a lot of graduates or trainee counselors every year is those with competency and qualification. Although the supervisor increases the level of competency and qualification of the trainee counselors, but how far the actual competency is achieved is still debatable (Falender, 2014). One of the reasons that contribute to this is because of the existence of the issues of role conflict and role ambiguity among the trainee counselors in supervision. Thus, the issue of the difficult role needs to be given due attention as it can affect the development of the trainee counselors and can cause problems to the clients (Kulp, 2012). Nonetheless, the literature review shows that the measurement tool to measure the difficult role of the trainee counselors in supervision is very limited. In Ladany \& Malouf (2010) also Bernard \& Goodyear (2014) there is a measurement tool that measures the role conflict and ambiguity of the 
trainee counselors in the supervision process so far, which is RCRAI. The problem arises when RCRAl is to be used for trainee counselors in Malaysia as it is originally built and constructed in foreign setting and surely there will be differences in the language and culture. Thus, RCRAI needs to be translated, its validity proven, also its reliability tested so that it will be more accurate and appropriate to be used in local studies. The objectives of this study are to:

a. Translate to measurement tool of Roles Conflict and Roles Ambiguity Inventory (RCRAI) from English version to English Language version.

b. Study the content validity of RCRAI

c. Study the reliability value of RCRAI

\section{Research Method \\ Research Design}

The study design is descriptive, aiming to translate, obtain the content validity and analyse the reliability of RCRAI. There are three main phases conducted in this study to achieve the objective; Phase I: translating the RCRAI; Phase II: getting the experts' evaluation on the content validity of RCRAl; and Phase III: conducting a pilot study to obtain RCRAI reliability value.

\section{Phase I}

Phase I is the stage of translating RCRAI measurement tool. The process of translating takes about six months. Researcher has identified six experts who have the qualification to translate. All the panel members have been contacted by the researcher to give their agreement about being the translators for RCRAI. When the agreement is obtained, only then that the letter of appointment is given to the panel members. All the experts are lecturers who have PhD in counseling psychology, and they are very good in both Malay and English Language. The translation procedure is done using the back translation process proposed by Brislin, Lonner and Thondike (1973). The process comprises of two stages and involves three translators for every stage. In the first stage, the original RCRAI will be translated to its Malay Language version. The translation of every item will be scrutinised and revised by researcher so that the meaning is standard and precise in the context of counseling and consistent, in terms of the local value and culture. The revision process is done towards the Malay Language RCRAI that is closest to original RCRAI. Having completed it, the next stage of translation will be taking place. In the second stage, the revised RCRAI in Malay Language is sent to three members of the panel for it to be retranslated back to English. After this is done, once more the researcher will go through the items and revise accordingly. Finally, only perfectly translated items and those which have the same meaning with the original ones will be retained. Having completed the back translation process, the RCRAI measurement tool will go through the second phase, or the content validity phase.

\section{Phase II}

Validity is an objective measurement to measure a concept in an empirical manner (Babbie, 2014) and it measures a quality or behaviour that it seeks to measure (Borderns \& Abott, 2014). A measurement is valid and can be applied if it can measure precisely the variables that are to be examined. According to Creswell (2008), any researcher needs to do the content validity of the measurement that is to be used by obtaining experts' agreement. Thus, in this study, four experts of the field were contacted and they were ready to carry out the content validity process of RCRAI. During this time, every evaluator will be given an evaluation form. 
The form will be marked by the evaluator, as to how far they agree to the content of the items and the sub-scale of RCRAI. There are 10 scales in the evaluation form with scale 1=strongly disagree to scale 10=strongly agree. Apart from that, the evaluation form also comprises of RCRAI in Malay and English versions also comment space for revision, criticism, or suggestions from evaluators. Any comment will be considered for improvement. To obtain the content validity value for every RCRAl item, the agreement value of every item from all experts have to be totalled and divided with the maximum number of agreement value. Meanwhile, to obtain the content validity value for every sub-scale which is role conflict (RC) and role ambiguity (RA), researcher will add the validity value of all items for every sub-scale, which is divided with the sub-scale items.

\section{Phase III}

The final phase which is phase III is where the researcher will test the RCRAI measurement test translated to see its reliability level. Reliability means that the scores obtained from an instrument are consistent and stable (Creswell, 2012; Pallant, 2010). In Sidek (2011) it is found that the reliability of a measurement tool is high if a variable or vision can be measured consistently by producing the same score, and by contrast, if the scores obtained differ from one another, it means that the measurement tool has low reliability and are inconsistent. One of the strategies to test the reliability instrument is through the pilot study (Creswell, 2012). To ensure that the RCRAI measurement tool is consistent, stable and reliable, a pilot study is carried out among trainee counselors $(n=30)$ at UPSI as at the time, UPSI was one single university that offered internship and supervision process on trainee counselors. Meanwhile, in the actual study, data have been gathered from among trainee counselors $(n=204)$ from nine public universities all across Malaysia.

\section{Research Area and Respondent}

In the first phase, the panel of translators are chosen from UNIMAS, UPSI, UPM, and USIM. Next, the evaluation experts for content validity in Phase II are appointed from UKM, UUM, and UIA. For the final phase which is Phase III, the data collection is done twice. The first data collection was among $n=30$ trainee counselors at UPSI. Whereas the second collection is in the actual study with $n=204$ trainee counselors doing first degree from the counseling program acknowledged by the Malaysian Counselor Board and Malaysia Qualification Accreditation (MQA). All these trainee counselors from nine public universities in Malaysia namely Universiti Putra Malaysia (UPM), Universiti Pendidikan Sultan Idris (UPSI), Universiti Sains Malaysia (USM), Universiti Malaya (UM), Universiti Utara Malaysia (UUM), Universiti Malaysia Sabah (UMS), Universiti Malaysia Sarawak (UNIMAS), Universiti Malaysia Terengganu (UMT), Universiti Sains Islam Malaysia (USIM), as well as Universiti Islam Antarabangsa Malaysia (UIAM). The respondents in this study selected through the stratified random sampling.

\section{Research Tools}

There are two measurement tools used in the study:

a) Roles Conflict and Roles Ambiguity Inventory (RCRAI) translated to Malay Language

b) Validation Evaluation Form with the scale from 1 to 10; scale 1 (strongly disagree) to scale 10 (strongly agree) 


\section{Research Findings}

\section{Phase I}

In phase I, this study has successfully translated RCRAI in English version to the RCRAI Malay Language version based on the translation procedure by Brislin et al (1973). This translated measurement tool represents the context of culture and which is appropriate with the value in Malaysia in specific. The total number of RCRAl items that have been translated to Malay Language still stay just like the English version of RCRAI constructed by Olk \& Friedlander, 1992. All in all, RCRAI measurement tool comprises of 29 items separated into two sub-scales which is role conflict totaling 13 items, and role ambiguity totalling 16 items. In the RCRAI, the scale used in 5-point Likert scale which is $1=$ not at all and $5=$ very much so. To calculate the RCRAl scores, all items in this measurement tool have to be added according to the respective sub-scales. In the RCRAI there is no negative item, so there is no score that needs to be reversed beforehand. The scores in the role conflict are divided into three levels namely low with the score range 13 to 29, moderate with the score range 30 to 47, and high with the score range 48 to 65 . Meanwhile, the score in the role ambiguity is also segregated into three levels, with the low score range 16 to 36 , moderate with the score range 37 to 58 , and high with the score range 59 to 80 . Table 1, 2, and 3 show the summary of the items, scoring method and the score interpretation of RCRAI:

Table 1: Sub-scale in RCRAl item

\begin{tabular}{|l|l|l|}
\hline Sub-scale & Item & \\
\hline Role conflict & $2,3,5,6,7,10,14,15,16,17,19,22,25$ & 13 \\
\hline Role ambiguity & $\begin{array}{l}1,4,8,9,11,12,13,18,20,21,23,24,26,27, \\
28,29\end{array}$ & 16 \\
\hline $\begin{array}{l}\text { Total number of } \\
\text { items }\end{array}$ & 29 \\
\hline
\end{tabular}

Table 2: RCRAI Scoring Method

\begin{tabular}{|l|l|l|}
\hline Scoring & Minimum score & Maximum score \\
\hline $\begin{array}{l}\text { Role-conflict sub-scale score can be } \\
\text { obtained by adding all scores of the items } \\
\text { that measure the sub-scale. }\end{array}$ & 65 \\
\hline $\begin{array}{l}\text { Role-ambiguity sub-scale score can be } \\
\text { obtained by adding all scores of the items } \\
\text { that measure the sub-scale. }\end{array}$ & 16 & 80 \\
\hline
\end{tabular}

Table 3: Score Interpretation of RCRAI

\begin{tabular}{|l|l|l|l|}
\hline Level of role-conflict & Score & $\begin{array}{l}\text { Level of Role } \\
\text { Ambiguity }\end{array}$ & Score \\
\hline Low & 13 until 29 & Low & 16 until 36 \\
\hline Moderate & 30 until 47 & Moderate & 37 until 58 \\
\hline High & 48 until 65 & High & 59 until 80 \\
\hline
\end{tabular}

\section{Phase II}

In phase II, a total of four experts have made the revision and reduced the degree of agreement together with several suggestions for the revision of items in the Malay version of 
the RCRAI. The validity procedure is based on Creswell (2008) who suggested that the researcher obtained the agreement of the experts when they evaluated the validity of the items and constructs of the measurement tool that is to be used. The agreement from four evaluators has been received and calculated from the validation evaluation form returned to the researcher. The coefficient value for every item, sub-scale and the whole item is shown in Table 4, 5, and 6.

Table 4: Coefficient value for every item

\begin{tabular}{|l|l|r|l|r|l|}
\hline Items & Coefficient value & Items & Coefficient value & Items & Coefficient value \\
\hline 1 & 0.80 & 11 & 0.90 & 21 & 0.93 \\
\hline 2 & 0.78 & 12 & 0.93 & 22 & 0.93 \\
\hline 3 & 0.83 & 13 & 0.93 & 23 & 0.93 \\
\hline 4 & 0.85 & 14 & 0.78 & 24 & 0.85 \\
\hline 5 & 0.93 & 15 & 0.80 & 25 & 0.93 \\
\hline 6 & 0.95 & 16 & 0.88 & 26 & 0.93 \\
\hline 7 & 0.85 & 17 & 0.88 & 27 & 0.88 \\
\hline 8 & 0.95 & 18 & 0.88 & 28 & 0.83 \\
\hline 9 & 0.93 & 19 & 0.90 & 29 & 0.95 \\
\hline 10 & 0.85 & 20 & 0.93 & & \\
\hline
\end{tabular}

Table 5: Coefficient value for each sub scales

\begin{tabular}{|c|c|c|c|}
\hline Items & Role Conflict's Coefficient value & Items & Role Ambiguity's Coefficient value \\
\hline 2 & 0.78 & 1 & 0.80 \\
\hline 3 & 0.83 & 4 & 0.85 \\
\hline 5 & 0.93 & 8 & 0.95 \\
\hline 6 & 0.95 & 9 & 0.93 \\
\hline 7 & 0.85 & 11 & 0.90 \\
\hline 10 & 0.85 & 12 & 0.93 \\
\hline 14 & 0.78 & 13 & 0.93 \\
\hline 15 & 0.80 & 18 & 0.88 \\
\hline 16 & 0.88 & 20 & 0.93 \\
\hline 17 & 0.88 & 21 & 0.93 \\
\hline 19 & 0.90 & 23 & 0.93 \\
\hline 22 & 0.93 & 24 & 0.85 \\
\hline \multirow[t]{5}{*}{25} & 0.93 & 26 & 0.93 \\
\hline & & 27 & 0.88 \\
\hline & & 28 & 0.83 \\
\hline & & 29 & 0.95 \\
\hline & $11.29 / 13=.87$ & & $14.4 / 16=.90$ \\
\hline
\end{tabular}

Table 5: Coefficient value for overall items 
If the value of the coefficient value of every item is .80 and above, it will enable all the item content to be accepted and it will have quality validity (Polit, Beck, dan Oven, 2007) The finding of this study proves that the items' coefficient value, the sub-scales and all of the RCRAl obtained is high and automatically, it will allow it to be used on the trainee counselors in the context of supervision in Malaysia.

\section{Phase III}

Phase III is the final phase which is to test the reliability of the RCRAI measurement tool. Thsi study refers to the reliability value using the Croanbach Alpha or coefficient $\alpha$ at the level of significance .05 . The coefficient $\alpha$ represents the strength of the relationship between the items of the measurement tool. The higher the value of $\alpha$, the higher the relationship between one item and another. This enables the assumption to be made that the measurement tool has the ability to measure the same construct. The interpretation of the coefficient $\alpha$ ais established in Table 5 as proposed in Cohen, Mannion \& Morrison (2007).

Table 5: The interpretation of the Croanbach Alpha Coefficient

\begin{tabular}{ll}
\hline Coefficient value $(\alpha)$ & Interpretation \\
\hline$>0.90$ & Very highly reliable \\
$0.80-0.90$ & Highly reliable \\
$0.70-0.79$ & Reliable \\
$0.60-0.69$ & Marginally/minimally reliable \\
$<0.60$ & Unacceptably low reliability \\
\hline
\end{tabular}

The finding of the reliability analysis shows that the RCRAI reliability value in both studies, namely the pilot study and the actual study is high, as shown in the table below:

Table 6: The RCRAI reliability value $(\alpha)$ in both study

\begin{tabular}{lll}
\hline Sub scale & Pilot test $(n=30)$ & Actual study $(n=204)$ \\
\hline Role conflict & .78 & .86 \\
Role ambiguity & .95 & .95 \\
\hline
\end{tabular}

Both the coefficient values $(\alpha)$ for every sub-scale of RCRAl exceed $\alpha>.60$. Based on Table 6 the reliability value in the pilot study for the sub-scale of role ambiguity $\alpha=.78$ and role conflict $\alpha=.95$, whereas in the actual study for the sub-scale of role ambiguity $\alpha=.86$ and role conflict $\alpha=.95$. It can be concluded that the RCRAl measurement tool is good and trustworthy, for the use of future studies in Malaysia.

\section{Discussion}

In counseling supervision, role conflict and role ambiguity are crucial to be given attention Bernard \& Goodyear (2019); Ahmed, Majid, Zin, Phulpoto, \& Umrani (2016); Olk \& Friedlander (1992) given that there is a significant correlation between both roles and the competency of the trainee counselors (Arifin et al., 2019). The role conflict in the supervision refers to the fact that the expectation or the behaviour of the trainee counselors towards the role that needs to be played is conflicting with one another as a student, counselor, or colleague, and when the supervisor's instruction are not the same as the personal judgment of the trainee counselors (Olk \& Friedlander,1992). Such a conflict happens, normally because of the difficulty of the trainee counselors to play two or more roles simultaneously. For example as a trainee, supervision is the best time to expose any weakness rectified by the 
supervisor but at the same time the trainee also plays his or her part as a counselor who conducts a session with a client, in which time he or she has to demonstrate the competency possessed. Meanwhile, role ambiguity is defined as the lack of clarity on the expectation on one's role, the way to fulfill the expectation further causing weak performance (Olk \& Friedlander, 1992).

Role ambiguity is commonly experienced by trainee counselors in the beginning (Olk \& Friedlander, 1992; Ronnestad \& Skovholt, 1993) as they are not sure about any personal issue that is suitable to be discussed in the supervision, how far can they go about exposing the issue, and the impact it has if he or she disagrees or not in the same line with supervisor's idea. Other than that, role ambiguity also happens when the trainee counselors are not clear about what they are expected to do or how they will be evaluated during the supervision (Bernard \& Goodyear, 2019; Olk \& Friedlander, 1992). To fulfill these multiple roles at any given time, this causes the role difficulty to the trainee counselors in supervision (Bernard \& Goodyear, 2019; Ellis et al., 2015; Stoltenberg \& McNeill, 2010).

This study is in tandem with the study by Arifin et al., (2019), whereby although role conflict and role ambiguity are important aspects, in past literature the studies on these two factors are very limited, especially in Malaysia. One of the causes is that there is a lack of measurement tool that is appropriate with the context and culture of this country. Thus, this sudy has successfully filled the gap in the literature review by translating Role Conflict and Role Ambiguity Inventory in the Malay Language version. With the right measurement tool for adaptation in the training field and counselor education in Malaysia, the supervision process in particular will be able to aid the researchers here to conduct their respective studies more conveniently.

Other than that, this study is consistent with the one done by Arifin et al., (2019) who translated the Evaluation Process Within Supervisory Inventory (EPSI) measurement tool using a standard translation process. The same process applies in this study where it translates the RCRAI measurement tool involving the forward, backward procedures and harmonization session such as revision and improvement of every item in terms of the language, sentence structure and the understanding of the terms in the measurement tool. The purpose is for the RCRAI translated to have the same meaning with the original one. Then, the tool is sent to have its validity and reliability checked before being distributed to the respondents in the actual study.

The study finding shows that the content validity values for all of the items and both the subscales of CRAI are high. The maximum value for the content validity of the RCRAl item is $=.95$ whereas the minimum value is $=.78$. For the content validity value of the sub-scale of role conflict it is $=.87$; role ambiguity $=.90$; and the overall content validity is $=.88$. Based on the validity values, it proves that the RCRAI measurement tool can measure well the role conflict and role ambiguity of the trainee counselors in the supervision in the context of this country. For the final finding, the reliability value of both sub-scales of RCRAI is also high in both the pilot study and the actual study. In the pilot study, the sub-scale of the role conflict obtains the value of $=.78$; and the sub-scale of role ambiguity has the value of $=.95$ For the actual study, the reliability value of the sub-scale of role conflict is $=.86$ whereas the role ambiguity is $=.95$. With the reliability value, once more this study has successfully proven that the RCRAI measurement tool is consistent. 


\section{Conclusion}

All in all, it can be concluded that the study done to translate the RCRAI measurement tool in the context and culture in Malaysia has successfully been carried out. Other than that, the finding also proves empirically that the RCRAI measurement tool has the content validity of the items and high quality reliability. With the measurement tool that measures the level of difficulty of the role of the trainee counselors in the supervision, not only helps the trainee counselors but also the supervisors to collectively identify the obstacles faced in the supervision session. Next, it can increase the level of competency of the trainee counselors produced in public universities and it can uphold the credibility of counseling professionalism in Malaysia in general.

\section{Corresponding Author}

Name: Suhaili Arifin

Affiliation: Program of Counseling and Psychology, Faculty of Business, Economics and Social Development, University Malaysia Terengganu, Malaysia

Country: Malaysia.

E-mail ID: suhaili@umt.edu.my

Address: Counseling and Psychology Department, Faculty of Business, Economics and Social Development, University Malaysia Terengganu, Malaysia

\section{References}

Ahmed, U., Majid, A. H. A., \& Zin, M. M. (2016). Moderation of meaningful work on the relationship of supervisor support and coworker support with work engagement. The Journal of Business, Economics, and Environmental Studies (JBEES), 6(3), 15-20.

Kaunselor, A. (1998). Akta 580, Undang-undang Malaysia. Kuala Lumpur. PNMB.

Arifin, S., Noah, S. M., Jaafar, W. M. W., \& Zakaria, N. S. (2019). The influence of the role conflict and role ambiguity towards counseling competency in supervision among trainee counselors in Malaysia. International Journal of Academic Research in Progressive Education and Development, 8(4), 77-90.

Bernard, J. M., \& Goodyear, R. K. (2019). Fundamentals of clinical supervision. (6 $6^{\text {th }}$ ed.). Upper Saddle River, NJ: Pearson.

Bordens, K., \& Abott, B. B. (2014). Research design and methods: A Process approach. (9th ed.). New York, NY: McGraw -Hill.

Bornsheuer-Boswell, J.N., Polonyi, M.M., \& Watts, R.E. ( 2013). Integrating Alderian and integrated developmental model approaches to supervision of counseling trainees. The Journal of Individual Psychology, 66 (4), 328-343.

Bradley, L. J., \& Ladany, N. (2001). Counselor supervision: Principles, process and practice ( $3^{\text {rd }}$ ed.). New York: Brunner-Routledge.

Brislin, R. W., Lonner, W. J., \& Thorndike, R. M. (1973). Cross-cultural research methods. New York: John Wiley \& Sons.

Cohen, L., Mannion, L., \& Morrison, K. (2007). Research Methods in education. (6 ${ }^{\text {th }}$ ed.). Abingdon: Routledge.

Creswell, J. W. (2008). Educational research: Planning, conducting, and evaluating quantitative and qualitative research (3rd ed.). Upper Saddle River, NJ: Pearson Education, Inc.

Creswell, J. W. (2012). Educational research: Planning, conducting and evaluating quantitative and qualitative research ( $4^{\text {th }}$ ed.). Boston: Pearson Education. 
Ellis, M. V., Hutman, H., \& Chapin, J. (2015). Reducing supervisee anxiety: Effects of a role induction intervention for clinical supervision. Journal of Counseling Psychology, 62(4), 608-620. https://doi.org/10.1037/cou0000099

Hess, A. K., Hess, K. D., \& Hess, T. H. (2008). Psychotherapy supervision: Theory, research, and practice. Hoboken, NJ: Wiley.

Holloway, E. L. (1984). Outcome evaluation in supervision research. The Counseling Psychologist, 12, 167-174.

Kementerian Pengajian Tinggi Malaysia. ( 2011). Hala tuju bidang kaunseling di Malaysia. Serdang. Universiti Putra Malaysia.

Kulp, L. E. (2012). Supervision Factors that Predict Trainee Role Conflict and Role Ambiguity. (Doctoral Dissertation The Lehigh University) Digital Dissertation 1334.

Ladany, N., \& Friedlander, M. L. (1995). The relationship between the supervisory working alliance and trainees' experience of role conflict and role ambiguity. Counselor Education and Supervision, 34(3), 220-231. https://doi.org/10.1002/j.15566978.1995.tb00244.x

Ladany, N., \& Malouf, M. A. (2010). Chapter 15, Understanding and conducting supervision research. 353- 388 in Ladany, N., \& Bradley, L.J. (2010). Counselor supervision. (4 ${ }^{\text {th }}$ ed.). Routledge, Taylor \& Francis Group, New York.

Lembaga Kaunselor Malaysia (2015). Piawaian dan Kelayakan Latihan Kaunselor. Putrajaya: Lembaga Kaunselor.

Olk, M., \& Friedlander, M. L. (1992). Role conflict and ambiguity in the supervisory experience of counselor trainees. Journal of Counseling Psychology, 39, 389-397.

Pallant, J. (2010). SPSS survival manual ( $1^{\text {st }}$ ed.). Buckingham Open University Press.

Polit, D. F., Beck, C. T., \& Owen, S. V. (2007). Is the CVI an acceptable indicator of content validity? Appraisal and recommendations. Research in Nursing \& Health, 30 (4), 459467.Ronnestad, M. H., \& Skovholt, T. M. (1993). Supervision of beginning and advanced graduate students of counseling and psychotherapy. Journal of Counseling \& Development, 71(4), 396-405. https://doi.org/10.1002/j.1556-6676.1993.tb02655.x

Noah, S. M. (2011). Reka bentuk penyelidikan: Falsafah, teori dan praktis. Serdang: Universiti Putra Malaysia.

Stoltenberg, C. D., \& McNeill, B. W. (2010). IDM supervision: An integrative developmental model for supervising counselors and therapists (3rd ed.). Routledge/Taylor \& Francis Group.

West, W. (2004). Learning from a qualitative study into counseling supervision: listening to supervisor and supervisee. Counseling and Psychotherapy Research, 4 (2), 20- 26. 